\title{
Impaired Intestinal Iron Absorption in Crohn's Disease Correlates with Disease Activity and Markers of Inflammation
}

\author{
Gaith Semrin, MD ${ }^{\star}, \S$, Douglas S. Fishman, MD ${ }^{\star}$, Athos Bousvaros, MD, MPH ${ }^{\star}$, Anna Zholudev, \\ MPH $^{*}$, Andrew C. Saunders, BS ${ }^{\dagger}$, Catherine E. Correia, BS ${ }^{\dagger}, \AA$, Elizabeta Nemeth, PhD $\|$, \\ Richard J. Grand, MD* ${ }^{*}$, and David A. Weinstein, MD, MMSc ${ }^{\prime}, \emptyset$ \\ "Center for Inflammatory Bowel Disease and Divisions of Gastroenterology and Nutrition, Boston, \\ Mass. \\ †Department of Medicine, General Clinical Research Center, Boston, Mass. \\ $\ddagger$ Clinical Research Program, Children’s Hospital, and Department of Pediatrics, Harvard Medical \\ School, Boston, Mass. \\ §Now with the Division of Gastroenterology and Nutrition, Children's Medical Center, Dallas, Tex \\ "Department of Medicine, University of California, Los Angeles \\ IDivision of Endocrinology, Department of Pediatrics, University of Florida, Gainesville
}

\begin{abstract}
Background-Anemia in patients with Crohn's disease (CD) is a common problem of multifactorial origin, including blood loss, mal-absorption of iron, and anemia of inflammation. Anemia of inflammation is caused by the effects of inflammatory cytokines [predominantly interleukin-6 (IL-6)] on iron transport in enterocytes and macrophages. We sought to elucidate alterations in iron absorption in pediatric patients with active and inactive CD.

Methods-Nineteen subjects with CD ( 8 female, 11 male patients) were recruited between April 2003 and June 2004. After an overnight fast, serum iron and hemoglobin levels, serum markers of inflammation [IL-6, C-reactive protein (CRP), and erythrocyte sedimentation rate], and a urine sample for hepcidin assay were obtained at $8 \mathrm{am}$. Ferrous sulfate $(1 \mathrm{mg} / \mathrm{kg})$ was administered orally, followed by determination of serum iron concentrations hourly for 4 hours after the ingestion of iron. An area under the curve for iron absorption was calculated for each patient data set.
\end{abstract}

Results-There was a strong inverse correlation between the area under the curve and IL-6 ( $P=$ $0.002)$ and area under the curve and CRP levels $(P=0.04)$. Similarly, the difference between baseline and 2-hour serum iron level $(\Delta[\mathrm{Fe}] 2 \mathrm{hr})$ correlated with IL-6 $(P=0.008)$ and CRP $(P=0.045)$. When cutoff values for IL-6 $(>5 \mathrm{pg} / \mathrm{mL})$ and CRP $(>1.0 \mathrm{mg} / \mathrm{dL})$ were used, urine hepcidin levels also positively correlated with IL-6 and CRP levels ( $P=0.003$ and 0.007 , respectively).

Conclusions-Subjects with active CD have impaired oral iron absorption and elevated IL-6 levels compared with subjects with inactive disease. These findings suggest that oral iron may be of limited benefit to these patients. Future study is needed to define the molecular basis for impaired iron absorption. 


\section{Keywords}

inflammatory bowel disease; hepcidin; interleukin-6; pediatric

Approximately $30 \%$ to $80 \%$ of subjects with Crohn's disease (CD) develop anemia as a complication of their illness (77\% in a recent pediatric cohort).$^{1-3}$ The anemia in these subjects is multifactorial and may be caused by lack of intake, chronic blood loss, micronutrient deficiency (iron, folate, and vitamin B12), hemolysis, and medication-induced myelosuppression. However, the 2 most common causes of anemia in CD subjects are iron deficiency and anemia of inflammation (ACI; also referred to as the anemia of chronic disease). Typical laboratory features of ACI include a normocytic or microcytic anemia, low serum iron level, low total iron binding capacity (TIBC), normal or high serum ferritin level, and high reticuloendothelial stores relative to the amount of total body iron. Oral iron therapy may be of limited or no benefit in subjects with ACI.

Although the exact pathogenesis of ACI is unknown, one hypothesis suggests that $\mathrm{ACI}$ arises in part as a result of a defect in the ability of enterocytes to transport iron and the of inability reticuloendothelial cells to recycle iron. Ferroportin (FPN), an iron export protein at the basolateral membrane of the enterocyte, is internalized and degraded under the influence of inflammatory cytokines (hepcidin and tumor necrosis factor- $\alpha$ ), thus blocking iron absorption at the intestinal level. ${ }^{4,5}$ The impaired transport of iron by the enterocyte results in a net decrease in intestinal iron absorption into the systemic circulation. In addition, there is increased phagocytosis of red cells by macrophages and impaired release of iron from cells of the reticuloendothelial system (e.g. macrophages) into the circulation. ${ }^{6}$ As a result, serum transferrin is decreased, and iron delivery to erythroid precursors is impaired, leading to a blunted erythropoietin response and a decreased response to iron therapy.

Hepcidin, a circulating peptide hormone produced by the liver and detectable in the urine, has been found to be induced by inflammation and iron overload. ${ }^{7,8}$ Animal studies have shown that loss of hepcidin causes iron overload, and excess hepcidin causes iron-deficiency anemia. 9-11 Excessive hepcidin production associated with large hepatic adenomas in patients with type Ia glycogen storage disease results in a severe refractory iron-deficiency anemia. These glycogen storage disease subjects do not respond to oral iron supplementation and have a limited response to intravenous iron dextran, similar to subjects with ACI. ${ }^{12}$ Thus, animal and human data indicate that hepcidin is a mediator of ACI acting on FPN to exert its effect. ${ }^{5,9}$

Hepcidin is induced by the cytokine interleukin-6 (IL-6), which is increased in subjects with $\mathrm{CD}$ and other inflammatory conditions. ${ }^{13-16}$

We hypothesized that iron absorption is impaired in subjects with active CD because inflammatory cytokines released by the inflamed bowel stimulate hepcidin release by the liver. The released hepcidin in turn impairs enterocyte iron absorption by downstream effects on DMT-1 and internalization and degradation of FPN, which leads to anemia. In this study, we compared iron absorption of subjects with active and inactive CD disease. To evaluate iron absorption in ACI, we used a diagnostic test previously developed to study iron-deficiency anemia in children. ${ }^{17,18} \mathrm{We}$ found that subjects with moderate to severe CD have impaired oral iron absorption and elevated IL-6 levels compared with subjects with inactive disease.

\section{METHODS}

\section{Subject Recruitment}

Subjects were recruited from the in-patient service and out-patient gastroenterology clinics of Children's Hospital (Boston, Mass). Subjects who enrolled in the study had the diagnosis of 
CD made by standard criteria. ${ }^{19}$ Other inclusion criteria were age between 5 and 25 years at the time of diagnosis and normal serum creatinine and vitamin E levels. Subjects were excluded if they had other concomitant inflammatory disorders, a serum creatinine level 1.5 times the upper limit of normal, or low serum vitamin $E$ levels (because of potential increased risk of hemolysis while performing the oral iron challenge test). The protocol was approved by the Children's Hospital Committee on Clinical Investigation. Informed consent was obtained from all subjects, and assent was obtained from all minors.

Subjects were studied in the General Clinical Research Center. Disease activity for each subject was assessed using the erythrocyte sedimentation rate (ESR) and serum C-reactive protein (CRP) and IL-6 levels. The normal values for these tests are $<20 \mathrm{~mm} / \mathrm{h}$ for ESR and $<1.0 \mathrm{mg} /$ $\mathrm{dL}$ for CRP. IL-6 levels were assessed because of the known relationship between IL- 6 and hepcidin, and IL-6 levels are known to be strongly linked to intestinal inflammation in patients with inflammatory bowel disease (IBD). 5,16 The upper limit of normal for IL- 6 was defined as $5 \mathrm{pg} / \mathrm{mL}^{14,15}$ because no normal subject had a serum IL-6 level $>5 \mathrm{pg} / \mathrm{mL}$ in past studies. We defined active disease as those with IL-6 levels $>5 \mathrm{pg} / \mathrm{mL}$ and inactive disease as IL-6 levels $<5 \mathrm{pg} / \mathrm{mL}$. A clinical activity score for each subject was also recorded using the Pediatric Crohn's Disease Activity Index (PCDAI) ${ }^{20}$ Complete blood counts, serum iron levels (normal, 50 to $120 \mu \mathrm{g} / \mathrm{L}$ ), and TIBC (normal, 250 to $420 \mu \mathrm{g} / \mathrm{dL}$ ) were measured in all subjects.

\section{Iron Absorption Test}

We modified the protocol used by Gross et $\mathrm{al}^{17}$ for the diagnosis of iron-deficiency anemia. The subjects fasted overnight. Baseline serum iron level and a urine sample for hepcidin assay were obtained at 8 am in the fasting state. Ferrous sulfate (dosed as $1 \mathrm{mg} / \mathrm{kg}$ elemental iron with a 60-mg maximum) was then administered orally as a liquid preparation, followed by determination of serum iron and TIBC concentrations hourly for 4 hours after the ingestion of iron. The area under the curve (AUC) for iron absorption was calculated as the sum of the areas under the trapezoids formed between time points of serum iron levels. The fasting (time 0 ) serum iron value served as the base of the trapezoid. The change in iron levels between baseline and 2 hours $(\Delta[\mathrm{Fe}] 2 \mathrm{hr})$ also was calculated.

\section{Laboratory Analysis of Cytokines}

The assay for serum IL-6 was performed with a commercially available enzyme-linked immunosorbent assay (Quantikine, R \& D Systems, Minneapolis, MN). Hepcidin urinary concentrations were determined by immunodot assay. ${ }^{21}$ Urine extracts equivalent to 0.1 to 0.5 $\mathrm{mg}$ of creatinine were dotted on Immobilon-P membrane (Millipore Corp, Bedford, Mass), along with a range of synthetic hepcidin standards ( 0 to $40 \mathrm{ng}$ ). Hepcidin was detected on the blots with rabbit anti-human hepcidin antibodies ${ }^{21}$ with goat anti-rabbit horseradish peroxidase as a secondary antibody. Dot blots were developed by the chemiluminescent detection method (SuperSignal West Pico Chemiluminescent Substrate, Pierce Chemical Co, Rockford, Ill) and quantified with the Chemi-doc cooled camera running Quantity One Software (BioRad Laboratories Inc, Hercules, Calif). The urinary hepcidin concentration was adjusted on the basis of the urinary creatinine concentration.

\section{Statistical Analysis}

The Mann-Whitney test was used to determine whether iron absorption was impaired in children with active $\mathrm{CD}$ using the AUC of the iron absorption test as the primary outcome variable. We compared the AUC in children with active CD (IL-6 levels $>5 \mathrm{pg} / \mathrm{mL}$ ) with that of subjects with inactive CD (IL-6 levels $<5 \mathrm{pg} / \mathrm{mL}$ ). As secondary outcome variables, we compared the AUC with CRP $(<1.0$ or $>1.0 \mathrm{mg} / \mathrm{dL})$ and urinary hepcidin $(<100 \mathrm{or}>100 \mathrm{ng} /$ $\mathrm{mg}$ creatinine). The Wilcoxon rank test was used to compare subjects with active and inactive $\mathrm{CD}$ in each data set. Spearman's correlation coefficient was used to determine the relationship 
between AUC, inflammatory cytokines, hepcidin, and acute-phase reactants. Spearman's correlation analysis also was performed to determine the linear relationship between AUC, $\Delta$ $[\mathrm{Fe}] 2 \mathrm{hr}$, and other characteristics of iron status. In addition, this test was used to determine the relationship between hepcidin expression and markers of iron absorption. Significance was defined as $P<0.05$. SPSS version 12.0.1 was used for statistical analysis.

\section{RESULTS}

\section{Subject Demographics}

We recruited 19 subjects with CD ( 8 female, 11 male patients) between April 2003 and June 2004. The clinical characteristics of the subjects are summarized in Table 1. One subject participated in the study twice, once when his disease was active and a second time when his disease was in remission. For purposes of data analysis, this subject's information from the "active" period was used, but the AUC from both the "active" and the "remission" periods is shown in Figure 1. Three other subjects were excluded for the following reasons: subject withdrawal after lost intravenous, mishandled blood sample, and an incorrect dose of ferrous sulfate. The subjects were receiving a variety of medications, including 5-aminosalicylate, corticosteroids, 6-mercaptopurine/azathioprine, and infliximab. Most subjects had ileocolonic involvement; 1 subject also had perianal disease, and 1 subject had clinically significant esophageal CD. At the time of study participation, 6 subjects had active CD (IL-6>5 pg/mL), and 9 had inactive $\mathrm{CD}$ (IL-6 $<5 \mathrm{pg} / \mathrm{mL})$.

\section{Laboratory Characteristics of Subjects}

Table 2 depicts the measures of inflammatory activity and iron status for all study subjects. Serum IL-6 levels divided the subjects into 2 distinct groups: those with IL- $6>5 \mathrm{pg} / \mathrm{mL}$ had a mean value of 20.5, and those with IL- $6<5 \mathrm{pg} / \mathrm{mL}$ had a mean value of $2.5 \mathrm{pg} / \mathrm{mL}$. The ESR and CRP levels also were significantly elevated when disease was active. During active disease, urinary hepcidin levels were elevated; during remission, however, urinary hepcidin levels decreased ( $295.3 \pm 177.3$ versus $31.2 \pm 48.4 ; P<0.003)$. A mean PCDAI score of 29.6 was calculated for patients with IL-6 levels $>5 \mathrm{pg} / \mathrm{mL}$ and 15.6 for patients with IL- $6<5 \mathrm{pg} / \mathrm{mL}$ $(P=\mathrm{NS})$. Because the mean PCDAI scores were not statistically different for active and inactive subjects, they were not used in further data analyses.

\section{Intestinal Iron Absorption Is Decreased in Subjects with Active CD}

Table 3 demonstrates the mean change in serum iron concentrations in subjects with active compared with those with inactive disease at different time points after the oral iron challenge. In those with active $\mathrm{CD}$, after a small increase in serum iron level at 1 hour after the oral dose, the hourly levels showed a steady decline to a nadir at 4 hours. In contrast, subjects with inactive $\mathrm{CD}$ demonstrated a brisk increase in serum iron values that was maintained for 4 hours. At each time point after baseline recordings, the mean serum iron value for subjects with active $\mathrm{CD}$ was statistically significantly lower than for those with inactive disease. Mean iron absorption as determined by the AUC was lower in subjects with active CD compared with those with inactive $\mathrm{CD}$ (Table 3 ). Similarly, $\Delta[\mathrm{Fe}] 2 \mathrm{hr}$ was significantly lower in subjects with active $\mathrm{CD}$ compared with those with inactive disease (Table 3 ).

Figure 1 demonstrates representative iron absorption curves in the same subject during 2 different periods: a period of active disease showing poor iron absorption and a period of remission showing recovery of iron absorption. 


\section{Relationships Between Tests of Iron Status and Markers of Inflammation}

As shown in Table 4, there was a strong inverse correlation between the AUC and the dichotomized IL- 6 and CRP levels. The value of $\Delta[\mathrm{Fe}] 2 \mathrm{hr}$ also was inversely correlated with IL-6 and CRP levels, whereas the urinary hepcidin concentrations showed a significant correlation with dichotomized IL-6 and CRP levels. The AUC, however, was not correlated with urinary hepcidin concentrations.

Using the Spearman coefficient we also showed statistically significant inverse linear correlations between the AUC and both IL- 6 and CRP. The $\Delta[\mathrm{Fe}] 2 \mathrm{hr}$ also showed an inverse correlation with both IL-6 and CRP. Urinary hepcidin concentrations correlated with serum IL-6 levels, whereas CRP levels did not. As in the analysis of dichotomized data, there was no significant correlation between the AUC and urinary hepcidin concentrations.

\section{DISCUSSION}

To the best of our knowledge, this is the first study to investigate the association between iron absorption, disease activity, and proinflammatory cytokines in children with $\mathrm{CD}$. We demonstrate that subjects with active $\mathrm{CD}$ have significantly impaired intestinal iron absorption compared with subjects with inactive disease. We also demonstrate a correlation between impaired oral iron absorption and serum IL-6 levels. Of clinical importance, both the AUC and the $\Delta[\mathrm{Fe}] 2 \mathrm{hr}$ showed significant correlation with serum IL-6 and CRP levels, providing potential therapeutically important information.

The oral iron absorption test, developed $>70$ years ago, has been used to evaluate iron uptake in children with iron-deficiency anemia. ${ }^{17,22}$ Children with iron deficiency characteristically demonstrate a robust rise ( $>100 \mu \mathrm{g} / \mathrm{dL})$ in serum iron concentration from 1 to 4 hours after an oral iron dose of $1 \mathrm{mg} / \mathrm{kg} .{ }^{17}$ In contrast, adult subjects with ACI demonstrate only small increases in serum iron after oral challenge, ${ }^{18}$ which would suggest impaired small intestinal iron absorption. Furthermore, analysis of bone marrow iron content in those subjects with a blunted response to the oral iron challenge demonstrated findings consistent with anemia of chronic disease rather than iron deficiency. ${ }^{18}$

In the present study, although frank anemia was not present in any subject, there were striking differences in iron absorption in subjects with active disease compared with those with inactive disease. Furthermore, the higher the IL-6 and CRP values and the lower the AUC and $\Delta[\mathrm{Fe}]$ $2 \mathrm{hr}$ were, the higher the likelihood of cytokine-induced impairment of iron absorption was.

The absorption of iron by the enterocyte is a complex process that has recently been reviewed by Fleming and Bacon. ${ }^{23}$ In brief, dietary ferrous iron $\left(\mathrm{Fe}^{2+}\right)$ is taken up from the apical surface of the enterocyte into the cytoplasm by the protein DMT-1 (divalent metal transporter). ${ }^{24-26}$ Once intracellular, iron can be either stored as ferritin or transported out of the basolateral surface of the cell into the circulation by FPN. ${ }^{26,27}$ In the circulation, iron is bound to transferrin and distributed to the liver and bone marrow, where it may be incorporated into hemoglobin. Free iron from senescent red cells phagocytosed by the reticuloendothelial system is incorporated into macrophages, from which it can then be released by FPN into the plasma, bound to transferrin, and recycled. ${ }^{6,28}$ In the presence of inflammatory cytokines, hepcidin downregulates FPN in the macrophage, trapping iron intracellularly.

As noted above, the peptide hepcidin is a key regulator of iron absorption by its action on FPN in the enterocyte and its release from macrophages. ${ }^{6,21,29}$ Hepcidin is a hormone primarily synthesized by hepatocytes, in which an 84-amino acid precursor protein (prohepcidin) is processed to the bioactive 25 -amino acids form found in circulation and urine. ${ }^{8,30}$ Studies in mice demonstrate that hepcidin inhibits intestinal iron absorption, ${ }^{9,11}$ placental iron transport, 
31 and the release of recycled iron from macrophages. ${ }^{11}$ In the human intestinal epithelial cell line, Caco-2, hepcidin decreases apical iron uptake and decreases expression of the DMT-1 apical transporter. ${ }^{4}$ In humans, production of excess hepcidin by liver adenomas in glycogen storage disease type Ia results in a profound anemia that is unresponsive to oral iron supplementation. ${ }^{32}$ In addition, a defective mutant hepcidin protein has been associated with increased iron absorption and juvenile hemochromatosis. ${ }^{33}$

Evidence now suggests that the proinflammatory cytokine IL-6 stimulates hepcidin release from the liver of mice and humans. ${ }^{34}$ In a murine model of inflammation, wild-type mice injected with turpentine exhibited increases in hepcidin mRNA and a reduction in serum iron, whereas IL-6-null mice did not. ${ }^{5}$ In addition, humans injected with recombinant human IL-6 exhibit increases in urinary hepcidin and reductions in serum iron. ${ }^{5}$ In human hepatocytes, hepcidin is induced by IL-6, but not IL-1 or tumor necrosis factor- $\alpha .{ }^{5,21}$ A number of studies have demonstrated increased serum IL-6 levels in CD. ${ }^{14,15}$ We hypothesize that the release of IL- 6 by the inflamed intestine stimulates hepcidin synthesis in the liver and that hepcidin inhibits intestinal iron absorption.

We used IL-6 levels rather than PCDAI to assess disease activity for several reasons: (1) Many aspects of the PCDAI, including abdominal pain, fatigue, and well-being, are influenced by noninflammatory factors; (2) other factors (e.g., perianal disease) may not correlate with systemic inflammation or iron absorption; and (3) 1 marker of PCDAI is anemia. Our study has a variety of implications for the management of IBD subjects. First, we have established a simple and straightforward means of identifying subjects with CD who may not respond to oral iron supplementation. Second, we have demonstrated that a lack of response to oral iron correlates well with IL-6 levels. Third, we provide evidence for a link between elevated urinary hepcidin level and reduced iron absorption in IBD. This study also indicates that control of disease activity is essential if a subject with active inflammation is to respond to oral iron supplementation. Further work is necessary to determine whether the oral iron absorption test and serum IL-6 level can predict a priori which IBD subjects will respond to iron supplementation and whether higher doses of ferrous sulfate can overcome the reduced absorption seen with the dose used in this study, as suggested by Lanzkowsky et $\mathrm{al}^{35}$ in children without IBD. Additional limitations of our study were the small sample size, lack of repeated measures, potential variations in the timing of urine processing, and the wide standard deviation in PCDAI among patients with active disease. ${ }^{20}$

We hope that this study will encourage further investigation into the pathogenesis of the anemia of chronic inflammation and perhaps encourage the development of new approaches to the treatment of anemia in children with IBD. Furthermore, future studies should focus on the relationship between iron status and urinary or serum hepcidin levels and the interactions with FPN and DMT-1. Such studies are currently underway in our IBD center.

\section{Acknowledgments}

The authors would like to thank Nancy Andrews, MD, PhD, for assistance in the planning phase of the study and Henry Feldman, $\mathrm{PhD}$, for consultation regarding statistical analysis. The authors also are indebted to their patients for participation in this project and to the nurses and staff of the General Clinical Research Center, Children's Hospital (Boston) for facilitating the study. The authors acknowledge with gratitude the Wolpow Family Fund for additional support.

Supported in part by NIH Pediatric Gastroenterology Training Grant T32 DK 07477, NIH General Clinical Research Center Grant M01 RR 02172, and Mentored Career Award (D.W.) K23 RR 017560. 


\section{REFERENCES}

1. Thayu MLM, Baldassano RN, Mamula P. Prevalence of anemia in incident pediatric Crohn disease. J Pediatr Gasteroenterol Nutr 2005;41:547.(Abstract)

2. Burbige EJ, Huang SH, Bayless TM. Clinical manifestations of Crohn's disease in children and adolescents. Pediatrics 1975;55:866-871. [PubMed: 1079596]

3. Wilson A, Reyes E, Ofman J. Prevalence and outcomes of anemia in inflammatory bowel disease: a systematic review of the literature. Am J Med 2004;116:44-49. [PubMed: 14706665]

4. Han, OW.; Weaver, V. Hepcidin down-regulates iron transport across the human intestinal cells. FASEB J 120: Progr Abstr \# 112.1; Presented at FASEB Meeting; April 2, 2006; San Francisco, CA. Available at: http://www.eb2006-online.com/pdfs/008702.PDF? PHPSESSID=f07543fef $8761587 \mathrm{~d} 860 \mathrm{af5e} 0239 \mathrm{a} 3 \mathrm{bf}$

5. Nemeth E, Rivera S, Gabayan V, et al. IL-6 mediates hypoferremia of inflammation by inducing the synthesis of the iron regulatory hormone hepcidin 10.1172/JCI200420945. J Clin Invest 2004;113:1271-1276. [PubMed: 15124018]

6. Knutson MD, Oukka M, Koss LM, et al. Iron release from macrophages after erythrophagocytosis is up-regulated by ferroportin 1 overexpression and down-regulated by hepcidin 10.1073/pnas. 0409409102. Proc Natl Acad Sci USA 2005;102:1324-1328. [PubMed: 15665091]

7. Fleming RE, Sly WS. Hepcidin: a putative iron-regulatory hormone relevant to hereditary hemochromatosis and the anemia of chronic disease. Proc Natl Acad Sci USA 2001;98:8160-8162. [PubMed: 11459944]

8. Park $\mathrm{CH}$, Valore EV, Waring AJ, et al. Hepcidin, a urinary antimicrobial peptide synthesized in the liver. J Biol Chem 2001;276:7806-7810. [PubMed: 11113131]

9. Rivera S, Nemeth E, Gabayan V, et al. Synthetic hepcidin causes rapid dose-dependent hypoferremia and is concentrated in ferroportin-containing organs. Blood 2005;106:2196-2199. [PubMed: 15933050]

10. Nicolas G, Bennoun M, Porteu A, et al. Severe iron deficiency anemia in transgenic mice expressing liver hepcidin. Proc Natl Acad Sci USA 2002;99:4596-4601. [PubMed: 11930010]

11. Nicolas G, Bennoun M, Devaux I, et al. Lack of hepcidin gene expression and severe tissue iron overload in upstream stimulatory factor 2 (USF2) knockout mice. Proc Natl Acad Sci USA 2001;98:8780-8785. [PubMed: 11447267]

12. Weinstein DA, Roy CN, Fleming MD, et al. Inappropriate expression of hepcidin is associated with iron refractory anemia: implications for the anemia of chronic disease. Blood 2002;100:3776-3781. [PubMed: 12393428]

13. Voulgari PV, Kolios G, Papadopoulos GK, et al. Role of cytokines in the pathogenesis of anemia of chronic disease in rheumatoid arthritis. Clin Immunol 1999;92:153-160. [PubMed: 10444359]

14. Bross DA, Leichtner AM, Zurakowski D, et al. Elevation of serum interleukin-6 but not serum-soluble interleukin-2 receptor in children with Crohn's disease. J Pediatr Gastroenterol Nutr 1996;23:164171. [PubMed: 8856584]

15. Gross V, Andus T, Caesar I, et al. Evidence for continuous stimulation of interleukin-6 production in Crohn's disease. Gastroenterology 1992;102:514-519. [PubMed: 1370661]

16. Hyams J, Fitzgerald J, Treem W, et al. Relationship of functional and antigenic interleukin 6 to disease activity in inflammatory bowel disease. Gastroenterology 1993;104:1285-1292. [PubMed: 7683293]

17. Gross SJ, Stuart MJ, Swender PT, et al. Malabsorption of iron in children with iron deficiency. J Pediatr 1976;88:795-799. [PubMed: 1271141]

18. Jensen NM, Brandsborg M, Boesen AM, et al. Low-dose oral iron absorption test in anaemic patients with and without iron deficiency determined by bone marrow iron content. Eur J Haematol 1999;63:103-111. [PubMed: 10480289]

19. Gasche C, Scholmerich J, Brynskov J, et al. A simple classification of Crohn's disease: report of the working party for the World Congresses of Gastroenterology, Vienna 1998. Inflamm Bowel Dis 2000;6:8-15. [PubMed: 10701144]

20. Hyams JS, Ferry GD, Mandel FS, et al. Development and validation of a pediatric Crohn's disease activity index. J Pediatr Gastroenterol Nutr 1991;12:439-447. [PubMed: 1678008] 
21. Nemeth E, Valore EV, Territo M, et al. Hepcidin, a putative mediator of anemia of inflammation, is a type II acute-phase protein. Blood 2003;101:2461-2463. [PubMed: 12433676]

22. Moore CV, Doan CA, Arrowsmith WR. Studies in iron transportation and metabolism, II: the mechanism of iron transportation: its significance in iron utilization in anemic states of varied etiology. J Clin Invest 1937;16:627-648. [PubMed: 16694510]

23. Fleming RE, Bacon BR. Orchestration of iron homeostasis. N Engl J Med 2005;352:1741-1744. [PubMed: 15858181]

24. Gunshin H, Mackenzie B, Berger UV, et al. Cloning and characterization of a mammalian protoncoupled metal-ion transporter. Nature 1997;388:482-488. [PubMed: 9242408]

25. Gunshin H, Allerson CR, Polycarpou-Schwarz M, et al. Iron-dependent regulation of the divalent metal ion transporter. FEBS Lett 2001;509:309-316. [PubMed: 11741608]

26. McKie AT, Marciani P, Rolfs A, et al. A novel duodenal iron-regulated transporter, IREG1, implicated in the basolateral transfer of iron to the circulation. Mol Cell 2000;5:299-309. [PubMed: 10882071]

27. Donovan A, Brownlie A, Zhou Y, et al. Positional cloning of zebrafish ferroportin1 identifies a conserved vertebrate iron exporter. Nature 2000;403:776-781. [PubMed: 10693807]

28. Knutson MD, Vafa MR, Haile DJ, et al. Iron loading and erythrophagocytosis increase ferroportin 1 (FPN1) expression in J774 macrophages. Blood 2003;102:4191-4197. [PubMed: 12907459]

29. Nemeth E, Tuttle MS, Powelson J, et al. Hepcidin regulates cellular iron efflux by binding to ferroportin and inducing its internalization. Science 2004;306:2090-2093. [PubMed: 15514116]

30. Krause A, Neitz S, Magert HJ, et al. LEAP-1, a novel highly disulfide-bonded human peptide, exhibits antimicrobial activity. FEBS Lett 2000;480:147-150. [PubMed: 11034317]

31. Nicolas G, Chauvet C, Viatte L, et al. The gene encoding the iron regulatory peptide hepcidin is regulated by anemia, hypoxia, and inflammation. J Clin Invest 2002;110:1037-1044. [PubMed: 12370282]

32. Weinstein DA, Roy CN, Fleming MD, et al. Inappropriate expression of hepcidin is associated with iron refractory anemia: implications for the anemia of chronic disease. Blood 2002;100:3776-3781. [PubMed: 12393428]

33. Huang FW, Pinkus JL, Pinkus GS, et al. A mouse model of juvenile hemochromatosis. J Clin Invest 2005;115:2187-2191. [PubMed: 16075059]

34. Yeh KY, Yeh M, Glass J. Hepcidin regulation of ferroportin 1 expression in the liver and intestine of the rat. Am J Physiol Gastrointest Liver Physiol 2004;286:G385-G394. [PubMed: 14592944]

35. Lanzkowsky P, Karayalcin G, Betkerur U, et al. Unreliability of the oral iron absorption test. J Pediatr 1977;90(3):494-496. [PubMed: 839351] 


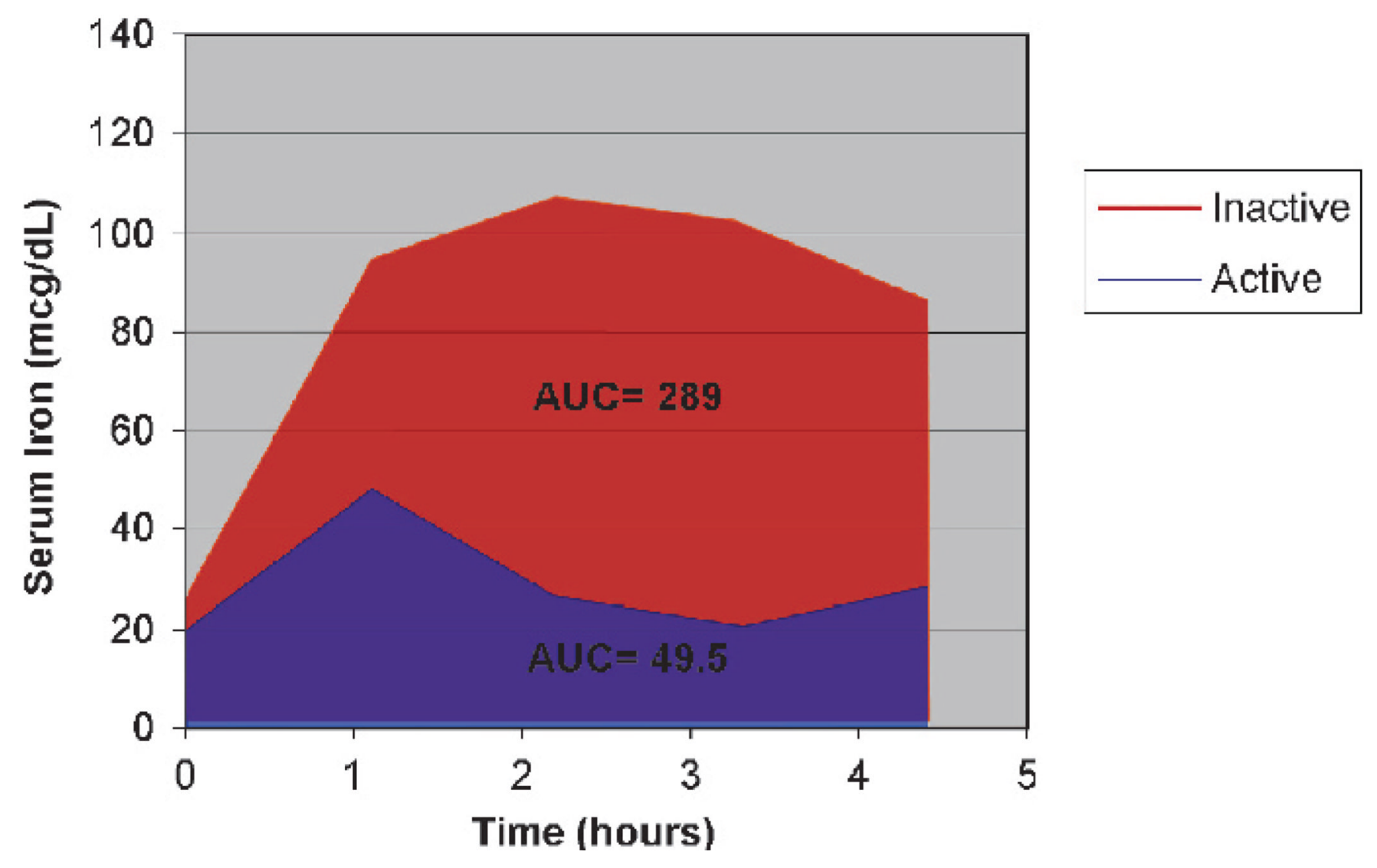

FIGURE 1.

Iron absorption in a single subject during periods of active and inactive disease. This 18-yearold male with CD received $1.0 \mathrm{mg} / \mathrm{kg}$ body weight at time 0 after fasting serum 
TABLE 1

Clinical Characteristics of the Subjects

\begin{tabular}{|c|c|c|}
\hline Patient Characteristics & $\begin{array}{c}\text { Active CD } \\
(\text { IL-6 }>5 \mathrm{pg} / \mathrm{mL})\end{array}$ & $\begin{array}{c}\text { Inactive/Mild CD } \\
(\text { IL-6 } \leq \mathbf{5} \text { pg/mL) }\end{array}$ \\
\hline \multicolumn{3}{|l|}{$\begin{array}{l}\text { Patients, no. } \\
\text { Gender, no. }\end{array}$} \\
\hline Male & 3 & 7 \\
\hline Female & 3 & 2 \\
\hline Mean PCDAI & 29.6 & 15.6 \\
\hline Mean age, years & 15 & 18 \\
\hline Range & $12-17$ & $14-21$ \\
\hline \multicolumn{3}{|l|}{ Disease distribution } \\
\hline Ileal only & 0 & 0 \\
\hline Ileocolonic & $5 / 6$ & $5 / 9$ \\
\hline Colonic & $1 / 6$ & $4 / 9$ \\
\hline \multicolumn{3}{|l|}{ Disease behavior } \\
\hline Mucosal & $6 / 6$ & $9 / 9$ \\
\hline Fistulizing & $2 / 6$ & $3 / 9$ \\
\hline Stricturing & $1 / 6$ & $3 / 9$ \\
\hline
\end{tabular}

Twelve of 15 subjects underwent upper endoscopy during the course of the disease. Only 2 of 12 had duodenal inflammation histologically. 


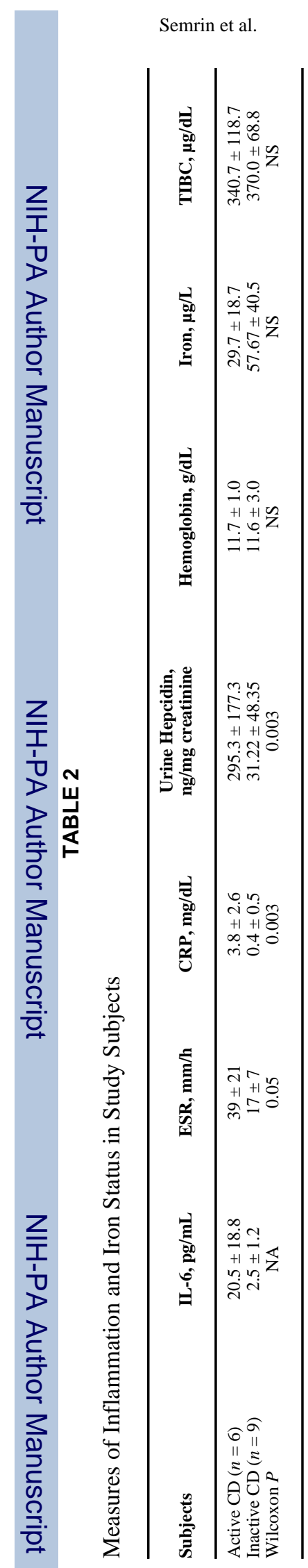

Inflamm Bowel Dis. Author manuscript; available in PMC 2009 December 3. 


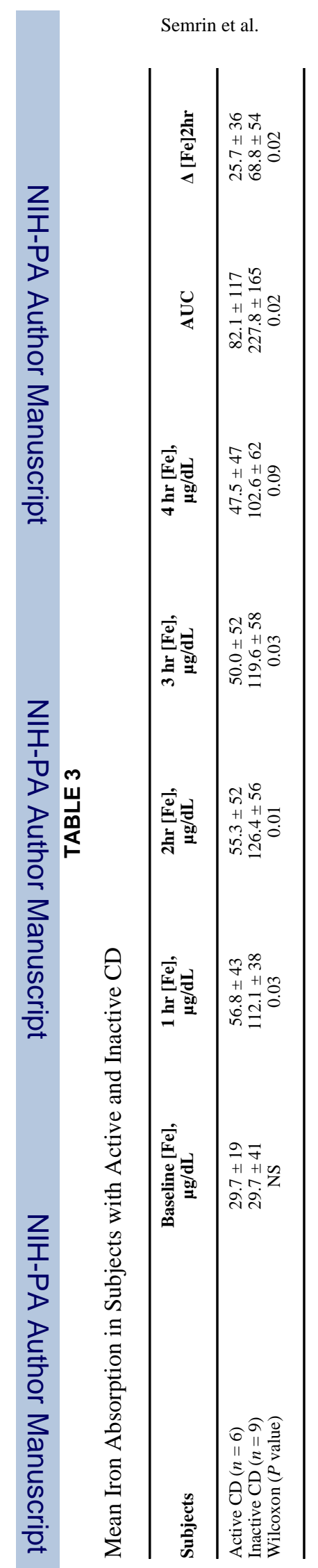

Inflamm Bowel Dis. Author manuscript; available in PMC 2009 December 3. 
TABLE 4

Nonlinear and Linear Correlation of Inflammatory Cytokines and Iron Absorption

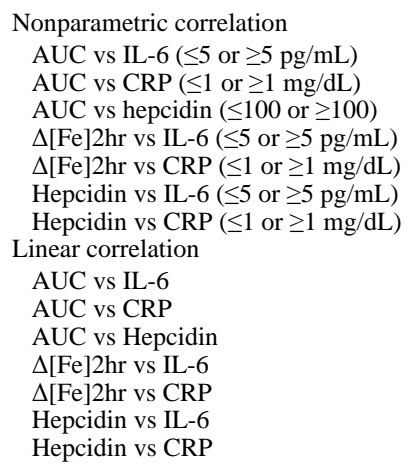

$\begin{array}{cc}P^{*} & \\ 0.018 & \\ 0.013 & \\ 0.064 & \\ 0.018 & \\ 0.010 & \\ 0.003 & \\ 0.007 & \\ \text { Spearman's } \rho & P^{*} \\ -0.720 & 0.002 \\ -0.534 & 0.040 \\ -0.386 & 0.155 \\ -0.654 & 0.008 \\ -0.524 & 0.045 \\ 0.665 & 0.007 \\ 0.405 & 0.134\end{array}$

${ }^{*} P<0.05$ is statistically significant (2-tailed values). 